\title{
A Customized Smart Home and Interior Design Concept Co-Designed with and for People with Autism Spectrum Disorder
}

\author{
Sandra Lisa LATTACHER ${ }^{\mathrm{a}, \mathrm{b}, 1}$, Lukas WOHOFSKY ${ }^{\mathrm{a}, \mathrm{b}}$, Philip SCHARF ${ }^{\mathrm{a}, \mathrm{b}}$ and Daniela \\ KRAINER ${ }^{\mathrm{a}, \mathrm{b}}$ \\ ${ }^{a}$ Research Unit Active \& Assisted Living at Carinthia University of Applied Sciences, \\ Klagenfurt, Austria \\ ${ }^{b}$ Institute for Applied Research on Ageing, Villach, Austria
}

\begin{abstract}
Autism spectrum disorder (ASD) diagnoses increased over the last decades, as reviews show comparing prevalence rates reported from different studies. Due to different effects of the disorder, personal support is required and provided by formal and/or informal caregivers in various activities of daily living. With the help of a customized smart home and interior design concept the aim is to enable people with ASD to live a more independent and self-reliant life. Following a participatory research approach, the end users are involved in the context of use and requirements definition, concept development, and later also in the implementation, and evaluation process. The solution shall assist end users in performing activities of daily living. The outcome of the work at hand is a set of modular functionalities (sensors, actuators, interior design solutions) to be integrated in a living environment specifically designed for people with ASD.
\end{abstract}

Keywords. Autism Spectrum Disorder, Smart Home, User-Centered Design, Stakeholder Analysis, Participatory Research, Assistive Technologies.

\section{Introduction}

Autism spectrum disorder (ASD) is a developmental disorder with a wide variation in the type and severity of symptoms. Referring to the Diagnostic and Statistical Manual of Mental Disorders (DSM-V), there are two main symptom complexes: difficulties with communication and social interactions, and restricted repetitive behavior, activities, or interests. Due to different effects of the disorder, individual support is required and provided by formal and/or informal caregivers in various activities of daily living (ADL) [1]. Although many assistive technologies for people with ASD can be found in literature [2], the field of home automation in combination with an interior design concept for people with ASD is, to the authors' knowledge, non-existent yet. Considering the whole path from initial user requirements to system design specifications, a concept of a customized smart home and interior design for assisted living is developed. This holistic approach is tailored to the needs of autistic people, aimed at increasing independency and self-reliance scalable to multifaceted life realities and diverse home environments.

\footnotetext{
${ }^{1}$ Corresponding Author: Sandra Lisa Lattacher, Research Unit Active \& Assisted Living at Carinthia University of Applied Sciences, Klagenfurt, Austria, s.lattacher@fh-kaernten.at
} 


\section{Methods}

Following a participatory research approach, the end users of the system (people with ASD, formal/informal caregivers) and associated stakeholders (architects, health professionals) were involved in the context of use and requirements definition, and the concept development based on DIN EN ISO 9241-210 [3]. Qualitative methods included individual remote focus groups targeting at various aspects of the users' life like daily routines, challenges and scenarios where smart gadgets and furnishings could support independent living. In addition, the experience of architects with the design of residential spaces and with following autism friendly design guidelines were obtained. Quantitative methods encompassed questionnaires, which were targeting at special sensitivity of individuals to thermal, acoustical, visual, and indoor air conditions.

\section{Results}

As a collective output, the most critical environmental factors that could trigger stress and tension were identified and corresponding technical, architectural, or combined solutions have been conceptualized, followed by a stakeholder validation of importance and usefulness and evaluation regarding feasibility and priority. The outcome is a set of modular functionalities, which covers solutions like crowd warnings, transition spaces or room condition regulation realized through sensors, actuators, and interior design components. [4]

\section{Discussion}

Through the continuous involvement, engagement, and participation of users we expect a sustainable, economic, and societal solution specifically designed for people with ASD and caregivers to support autonomous living. We facilitate the flow back of benefits to the end users that are in the center of our research. As a next step, the sensor technology and architectural components will be implemented, integrated, and tested in a demo apartment in a lab setting.

The research leading to these results is co-financed by the European Regional Development Fund under the framework of INTERREG IT-AT (SENSHOME project).

\section{References}

[1] I. Kamp-Becker and S. Bölte, Autismus, 2. Auflage. München Basel: Ernst Reinhardt, 2014.

[2] M. H. Black et al., 'The use of wearable technology to measure and support abilities, disabilities and functional skills in autistic youth: a scoping review', Scand. J. Child Adolesc. Psychiatry Psychol., vol. 8, pp. 48-69, 2020, doi: 10.21307/sjcapp-2020-006.

[3] ISO 9241-210, 'Ergonomics of human-system interaction — Part 210: Human-centred design for interactive systems'. 2019.

[4] S. L. Lattacher, 'Participatory Research in the Development of a Smart Home Environment for People on the Autism Spectrum - Barriers, Methods and Opportunities during a Pandemic', presented at the 2nd International Workshop on Indoor Comfort, online, Dec. 09, 2020, Accessed: Mar. 11, 2021. [Online]. Available: https://forschung.fh-kaernten.at/aal/en/senshome/workshop-indoor-comfort/. 